\title{
Correlations between Attention, Emotional Distress and Anxiety with Regards to Athletes of 11-15 Years in Perceptual-motor Sports
}

\author{
Emilia Florina Grosu ${ }^{1, *}$, Vlad Teodor Grosu², Dan Monea ${ }^{1}$ \\ ${ }^{1}$ Department of Individual Sport, Faculty of Physical Education and Sport, Bolyai University, Romania \\ ${ }^{2}$ Department of Mechatronics and Machine Dynamics, Mechanic Faculty, Technical University, Romania
}

Copyright $(\mathcal{C} 2015$ by authors, all rights reserved. Authors agree that this article remains permanently open access under the terms of the Creative Commons Attribution License 4.0 International License

\begin{abstract}
Problem Statement: tests were applied on athletes aged between $11 \pm 5$ and $15 \pm 3$. The group of athletes is part of the Romanian Olympic Judo team and ski groups of sports clubs in Gheorgheni (HR), Baia-Sprie (MM), Toplița (HR), Sibiu (SB) and Petrosani (HD). Purpose of Study: through this study, we analyse the correlations between the three psychological processes: emotional distress, attention and anxiety. Methods: the methods we have applied contain the following tests: AM concentration and attention, AD - distributive attention, AP - perceptive attention, EMAS - emotional distress, PDE anxiety. These were the initial tests we have used as starting points in our research. The purpose was to increase the sports performance through the application of mental training techniques. Findings and Results: to compare the scores / ranks on cognitive tests applied to the two groups of athletes, we have used nonparametric Mann-Whitney test (U) for unpaired samples. Materiality was $\alpha=0.05(5 \%), \alpha=0.01$ ( $1 \%$ ) or $\alpha=0.001$. To detect the correlation between two quantitative variables, we continued by using the Spearman rank correlation coefficient of $(\rho)$. The analysis of correlation between coefficients was performed using Colton's rule. Polynomial regression was the method used to derive the mathematical equation of dependence of a continuous variable by another variable. Conclusions and Recommendations: the comparative analysis of the cognitive test scores applied on studied groups with statistical significance revealed positive correlations; except for the group ski EMAS, where the test values were negative.
\end{abstract}

Keywords Alpine Ski, Athletes, Emotional Distress, Anxiety, Attention

\section{Problem Statement}

We approach this issue from the perspective of the
Olympic Judo team, which recorded great performances on a global level, and of the group of skiers, which recorded lower performances, because of the training conditions (there are only 3-4 months of snow in Romania). Because skis are so slippery fore and aft, balancing on them in the sagittal plane is much different than most other situations [8]. (LeMaster, 2010, p. 83). A controlled action must be "conscious", which means that athletes must be absolutely present and concentrated on what they are doing. This should exclude all distraction from interfering. That is the first point [10]. (Vittoz, Godefroy, 2001, p. 45).

The tests were applied on athletes aged between $11 \pm 5$ and $15 \pm 3$. The group of athletes is part of the Romanian Olympic Judo team and ski groups of sports clubs in Gheorgheni (HR), Baia-Sprie (MM), Toplița (HR), Sibiu (SB) and Petrosani (HD). Skiers with open minds and keen body awareness can often change their movement patterns on the fly, but many depend on trusted coaches for corrective feedback and kinaesthetic cues [6]. (Fellow, 2011, p. 19)

\section{Purpose of Study}

Through this study, we analyse the correlations between the three psychological processes: emotional distress, attention and anxiety. We applied these tests to monitor the athletes' capacity to focus. Mental training can help athletes during their training, by allowing them to acquire better motor capacity [3]. (Chevallier, 1988/10)

\section{The Methods}

We have applied contain the following tests: AM concentration and attention, $\mathrm{AD}$ - distributive attention, $\mathrm{AP}$ - perceptive attention, EMAS - anxiety, PDE - emotional distress. Stress is defined as the expression of our reactions to the measure of our adaptation to a change we must make 
[2]. (Chevallon, 2007, p. 17) For the EMAS test, respondents were asked to use the five-point assessment scale for answering to each item [5]. (after Endler, Edwards, Vitelli, 2002). These were the initial tests we have used as starting points in our research. The purpose was to increase the sports performance through the application of mental training techniques.

Focusing techniques through visualization are considered very efficient and they make up, mentally, the complex movements from their elementary parts, as if the athlete were able to review the motor gesture in slow motion [1]. (Brugnoli, 2005, p. 35).

Statistical indicators: we calculated elements of descriptive statistics and we presented the data by using centrality, localisation and distribution indicators.

Statistical analysis: for comparing the scores / ranks in cognitive tests applied to the two groups of athletes, used nonparametric Mann-Whitney test $(\mathrm{U})$ for unpaired samples. We obtained a materiality threshold of $\alpha=0.05(5 \%), \alpha=$ $0.01(1 \%)$ or $\alpha=0.001$, as follows:

\section{Findings and Results}

To compare the scores / ranks in cognitive tests applied to the two groups of athletes, we have used nonparametric Mann-Whitney test $(\mathrm{U})$ for unpaired samples.
Materiality was $\alpha=0.05(5 \%), \alpha=0.01(1 \%)$ or $\alpha=0.001$, as follows: $0.01<\mathrm{p}<0.05$ - statistically significant difference; $0.001<p<0.01$ - very significant difference statistically; $p<0.001$ - highly significant differences statistically; $p>0.05$ - statistically insignificant difference.

To detect the correlation between two quantitative variables, we continued by using the Spearman rank correlation coefficient of $(\rho)$. The analysis of correlation between coefficients was performed using Colton's rule. Polynomial regression was the method used to derive the mathematical equation of dependence of a continuous variable by another variable.

Upon the statistical analysis of scores in the two cognitive tests applied to the two groups, (unpaired samples), we noticed the following:

- for the MA test - lack of statistically significant differences between the two groups $(p>0.05)$

- for the AP2 test - lack of statistically significant differences between the two groups $(p>0.05)$

- for the $\mathrm{AD}$ test - highly significant differences statistically between the two groups $(p<0.001)$

- for the PDE test - statistically significant differences between the two groups $(p<0.05)$

for the EMAS test - highly significant differences statistically between the two groups $(\mathrm{p}<0.001)$.

Table 1. Comparative analysis of scores obtained by the groups in cognitive tests and the statistical significance

\begin{tabular}{|c|c|c|c|c|c|c|c|c|}
\hline Sample & Test & Mean & SE & Median & SD & Min. & Max. & $\begin{array}{c}\text { Statistical significance } \\
(p) \\
\text { Judo vs. Ski }\end{array}$ \\
\hline \multirow{5}{*}{ Judo } & MA & 43.6154 & 2.9473 & 48 & 10.6265 & 14 & 50 & \multirow{2}{*}{ MA: 0.0521} \\
\hline & AP2 & 16.6923 & 1.0824 & 17 & 3.9027 & 7 & 21 & \\
\hline & $\mathrm{AD}$ & 0.4254 & 0.0267 & 0.38 & 0.0963 & 0.28 & 0.63 & \multirow{2}{*}{ AP2: 0.1949} \\
\hline & PDE & 25.5385 & 3.9526 & 21 & 14.2514 & 12 & 65 & \\
\hline & EMAS & 32.6923 & 2.1255 & 32 & 7.6636 & 21 & 50 & \multirow{2}{*}{ AD: 0.0001} \\
\hline \multirow{5}{*}{ Ski } & MA & 36.9697 & 1.9111 & 38 & 10.9786 & 14 & 50 & \\
\hline & AP2 & 15.25 & 0.6795 & 15 & 3.8437 & 7 & 21 & \multirow{2}{*}{ PDE: 0.0312} \\
\hline & $\mathrm{AD}$ & 0.2394 & 0.0252 & 0.24 & 0.1424 & 0 & 0.5 & \\
\hline & PDE & 28.9063 & 1.4874 & 25.5 & 8.4141 & 20 & 58 & \multirow{2}{*}{ EMAS: $<0.0001$} \\
\hline & EMAS & 18.625 & 2.1495 & 17.5 & 12.1596 & 2 & 54 & \\
\hline
\end{tabular}

Table 2. Correlation statistical analysis between the scores of tests applied to the tow groups

\begin{tabular}{ccccc}
\hline Tests & Judo & \multicolumn{2}{c}{ Ski } \\
\hline MA - PDE & 0.3194 & $* *$ & 0.2440 & $*$ \\
AP2 - PDE & 0.1514 & $*$ & -0.2799 & $* *$ \\
AD - PDE & 0.3540 & $* *$ & -0.2652 & $* *$ \\
PDE - EMAS & 0.2390 & $* *$ & 0.3959 & $* *$ \\
\hline
\end{tabular}

Regarding the judo team, the correlation statistical analysis between the scores /ranks to the tests studied revealed the following:

- acceptable, but reversed correlation between AP2 - EMAS.

- acceptable and direct correlation between MA - PDE, see Fig. 1. 


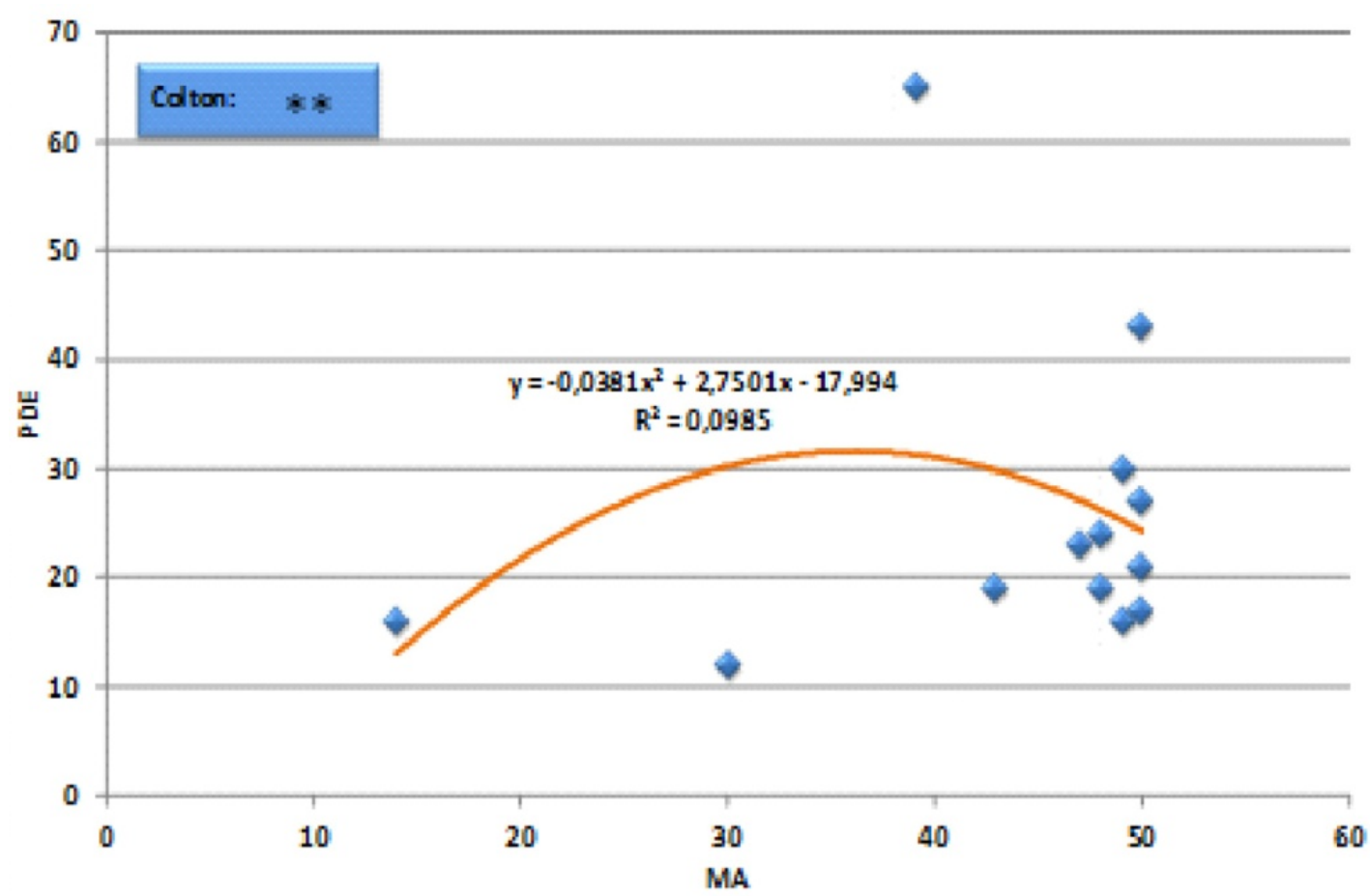

Figure 1. Judo - correlation between concentration and attention (MA) and emotional distress (PDE)

- acceptable and direct correlation between AD - PDE.

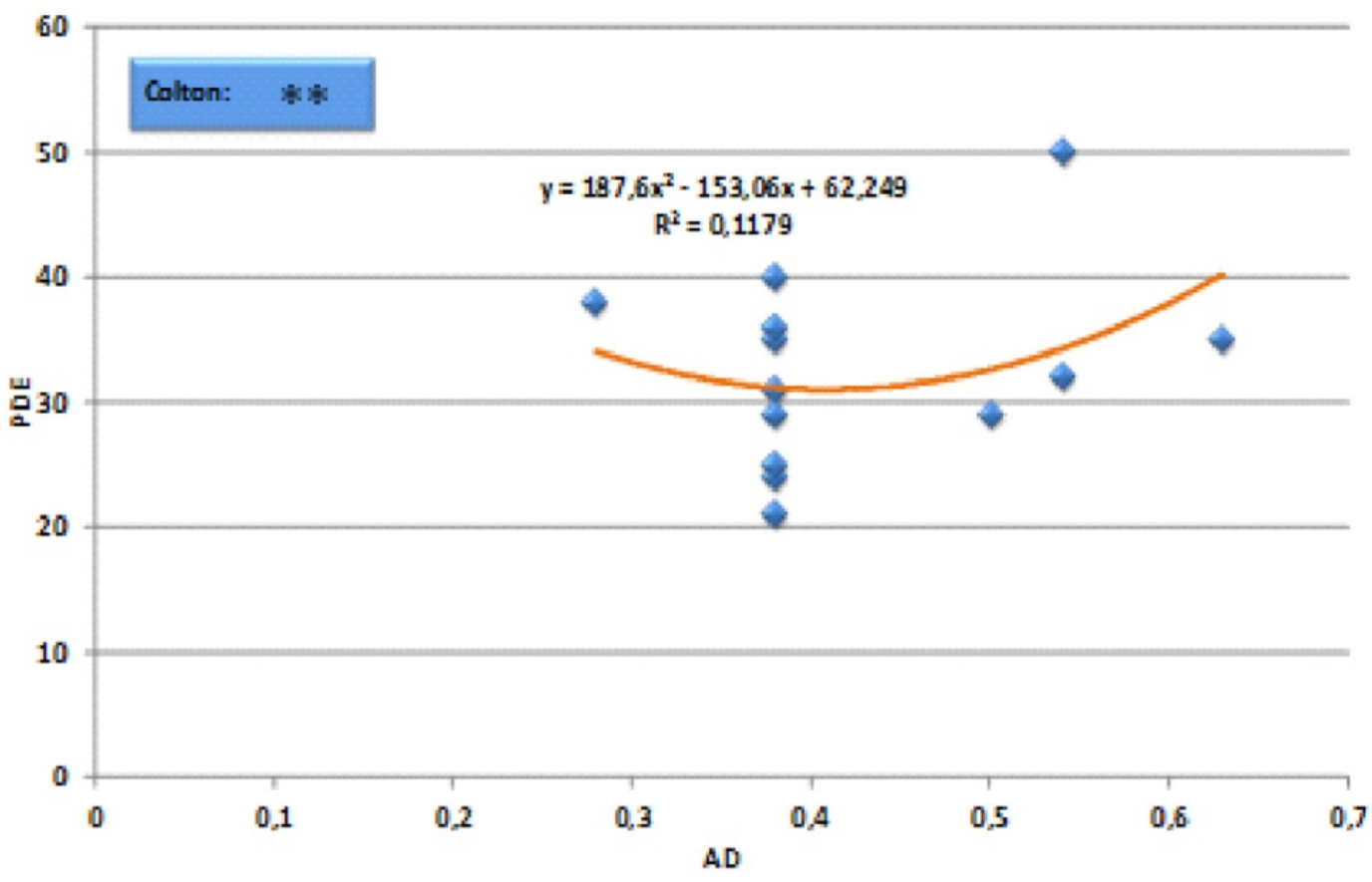

Figure 2. Judo - correlation between distributive attention (AD) and emotional distress (PDE)

For the ski group, the correlation analysis between the scores / ranks in the tests studied showed as follows:

Good and direct correlation between AP2 and AD, see Fig. 3. All athletes are aware of how important it is to focus your mind on a goal. In fact, without such focus, it would be very difficult to win [7]. (Garratt, 2011, p. 177).

Acceptable, but reversed correlation between AP2 and PDE. This means that, in skiers, an increase in the spirit of observation and in perceptive attention determines a decrease in emotional distress. The fact is proven by the most common procedure in slalom: "cross-block", which consists of clearing the gate with the outside arm.

If executed correctly, this procedure allows the athletes to slip very near to the [9]. (Ștefănescu, 2010, p. 61). 


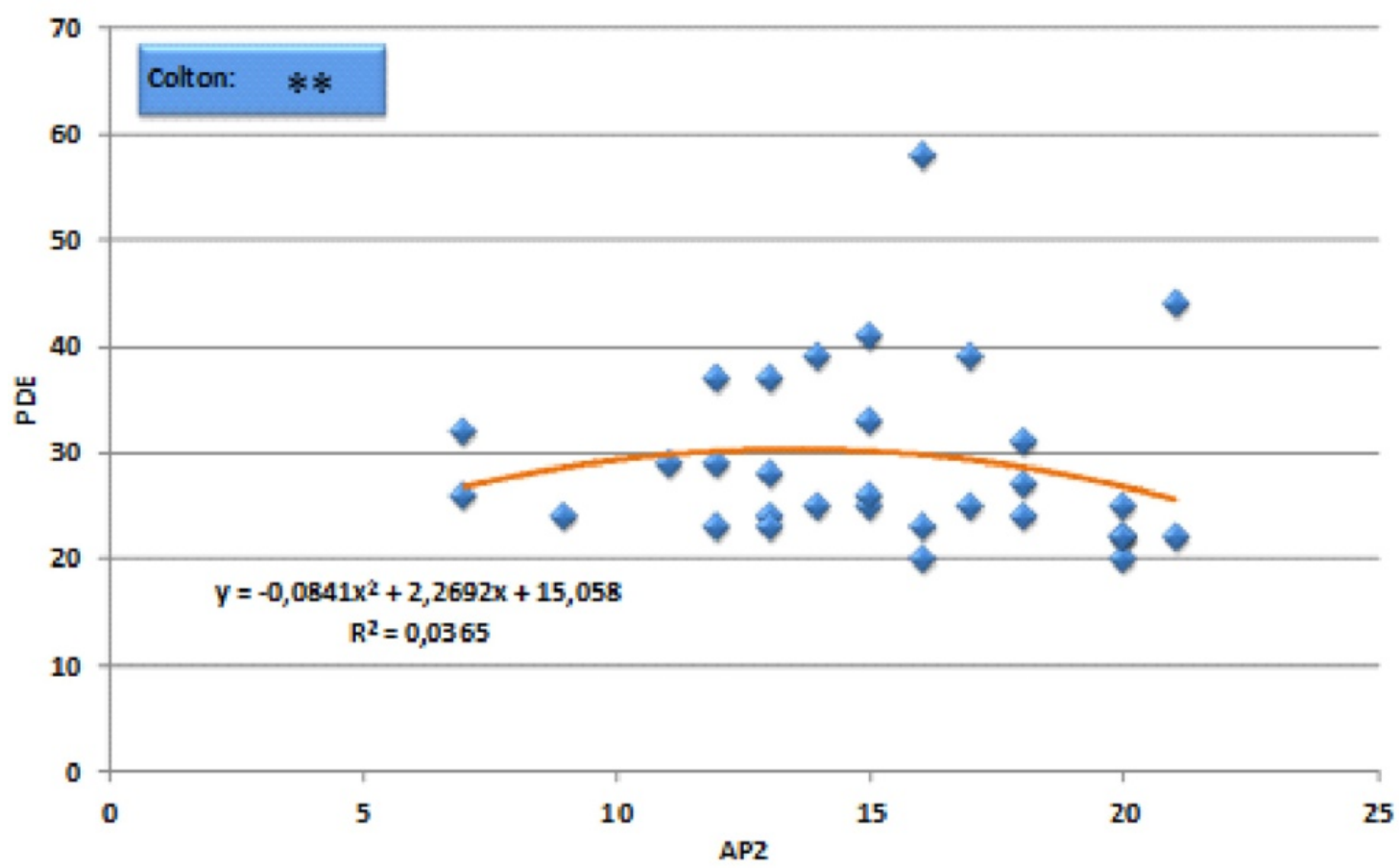

Figure 3. Ski - correlation between perceptive attention, spirit of observation (AP2) and emotional distress (PDE)

- acceptable, but reversed correlation between AD and PDE, see Fig. 4.

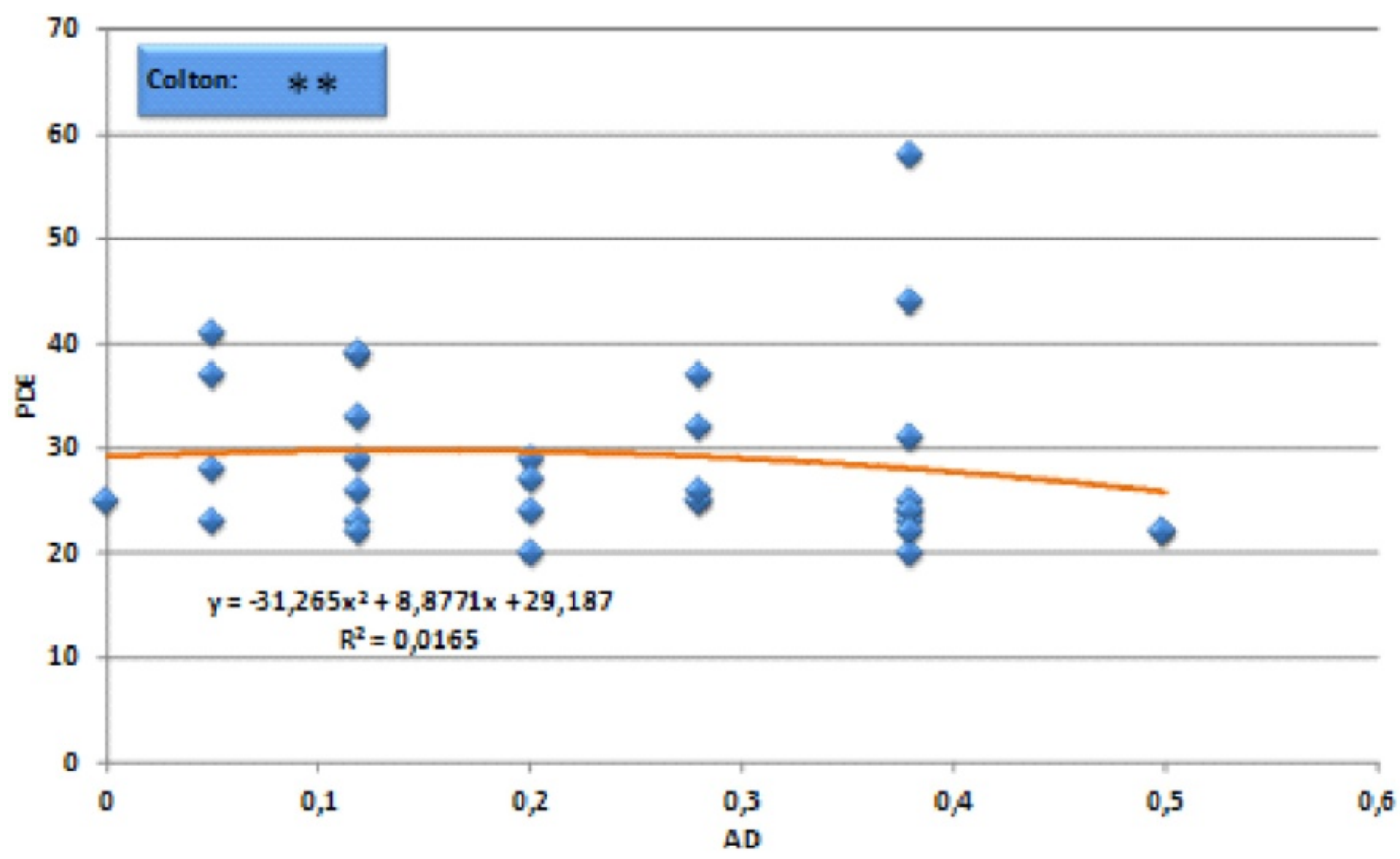

Figure 4. Ski - correlation between perceptive attention (AD) and emotional distress (PDE)

Acceptable and direct correlation between MA - EMAS, AD - EMAS and PDE - EMAS, as illustrated in Fig. 5 below. This means that the increase in emotional distress leads to an increase in anxiety. 


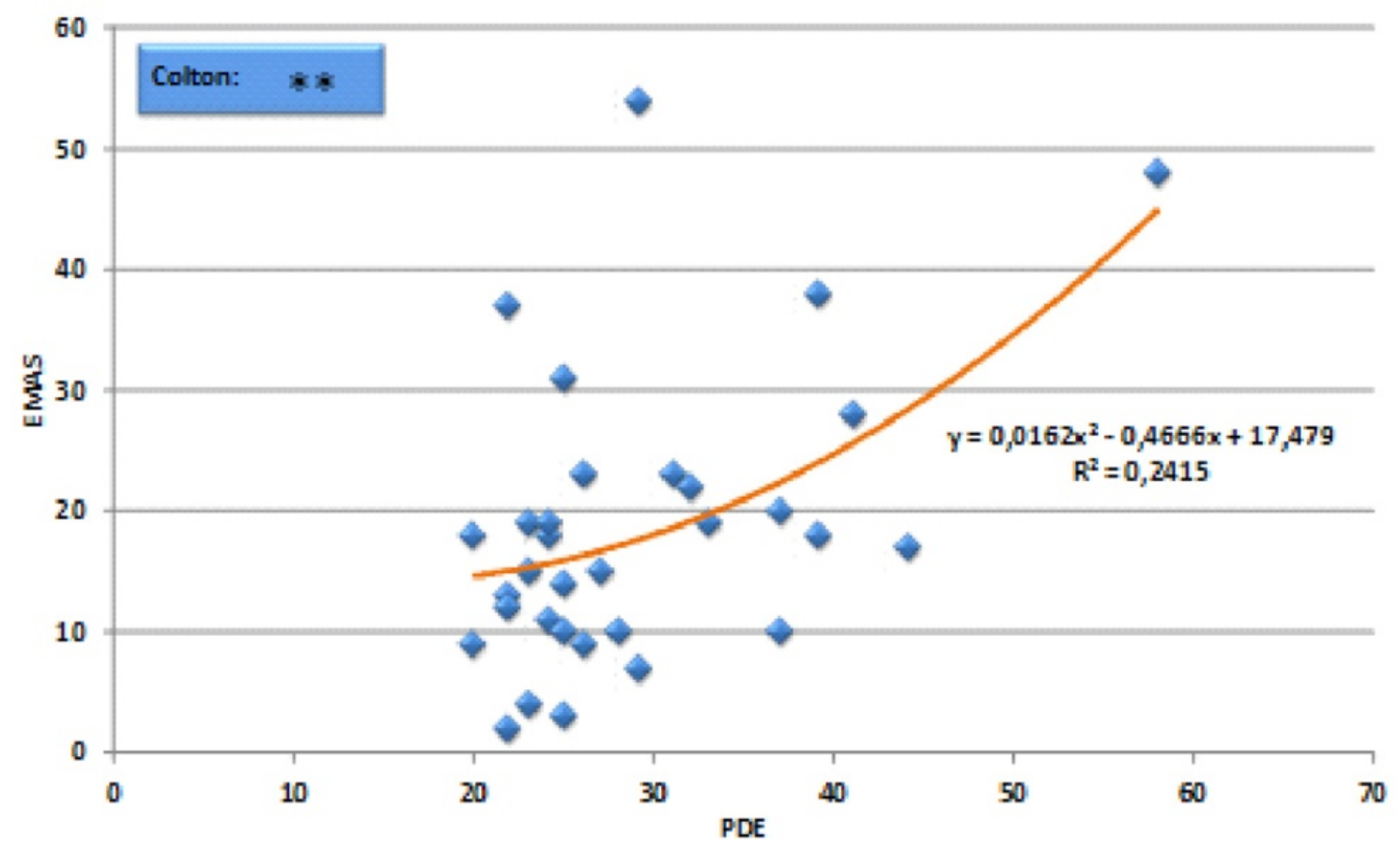

Figure 5. Ski - correlation between emotional distress (PDE) and anxiety (EMAS)

\section{Conclusions and Recommendations}

The comparative analysis of the cognitive test scores applied on studied groups with statistical significance revealed positive correlations; except for the group ski EMAS, where the test values were negative. The correlation coefficient according to Colton is AP2 - PDE in the ski group; it is negative $(-0.2799)$ and the correlation is acceptable. The correlation between perceptive attention, spirit of observation and emotional distress is negative, which means that, while attention values increase, values of emotional distress decrease; hence, athletes will perceive less emotional distress in the relation AP2 - PDE. In addition, it is worth underscoring the negative correlation coefficient between AD - PDE (-0.2652), which implies an acceptable correlation, recorded in the ski group. As a conclusion, we cite Elling "Being mellow in mind and movement is the underlying key to being able to perform properly" [4]. (2003, p. 159).

\section{REFERENCES}

[1] Brugnoli, M., P., (2005). Techniche di mental Training nello Sport, Vincere la tensione aumentare la concentrazione e la performance agonistica, Red Edizioni, Milan, p. 35

[2] Chevallon, S., (2007). La preparazione psicologica dello sportivo, La motivazione, la ricerca del suuceso, il miglioramento delle performance, Edit. DeVecchi Editore, Milano, p. 17

[3] Chevallier, Nicole, (1988). Vers une compréhension des processus d'imagerie et de répétition mentale des athlètes dans leur préparation psychologique, Journal Science $d u$ Sport, vol. 8, no. 10, ottombre.

[4] Elling, Mark, R., (2003). The All-Mountain Skiers, Second Edition, The Way to Expert Skiing, Ragged Mountain Press, P. O. Box 220, Camden, ME 04843, Printed. USA, p. 159

[5] Endler, N., S., Edwards J., M., Vitelli,R., (2002). EMAS Social Anxiety Scales (EMAS -SAS). Manual Extension for The Endler Multidimensional Anxiety Scales, Western Psychological Services, 12031 Wilshine Boulevard, Los Angeles, California 90025-1251.

[6] Fellows, C., (2011). Total Skiing, The proven pyramid approach for improving functional movement, fitness, technique, tactics, Human Kinetics, United States, P. O. Box 5076, Champaign, IL 61825-5076 800-747-4457, p. 19.

[7] Garratt, Ted, (2011). PNL per lo sport, Come allenare la mente per vincere con la programmzione neuro-linguistica, Editura Alessio Roberti,

[8] LeMaster Ron, (2010). Ultimate Skiing, Master the techniques of great skiing, Human Kinetics, Copyright (C) by Blue Sky, Inc, p. 83, Web site: www.HumanKinetics.com

[9] Ștefănescu. H., (2010). Optimizarea pregătirii schiului alpin actual, Napoca Star, Cluj - Napoca, p. 61

[10] Vittoz, R., Godefroy C., H., (2001), Treatment Of Psycho Neuroses Through Re-Education of Cerebral Control, (C) IAB, Manufactured in the U.S.A. 